\title{
Experimental Investigation of New Design Concepts for the Tribological Contact between the Valve Plate and the Cylinder Block in Axial Piston Machines
}

\author{
Stefan Geffroy*, Stephan Wegner**, Stefan Gels***, Katharina Schmitz* \\ *Institute for Fluid Power Drives and Systems, RWTH-Aachen University, Campus-Boulevard 30, 52074 Aachen \\ E-mail: S.Geffroy@ifas.rwth-aachen.de \\ **Stackpole Powertrain International GmbH, Campus-Boulevard 30, 52074 Aachen \\ ***Hydraulische Antriebstechnik P\&G GmbH, Nettestraße 39, 58762 Altena
}

\begin{abstract}
Axial piston machines are widely used in both stationary and mobile hydraulic systems due to their efficiency and robustness in high pressure applications. Important tribological contacts in axial piston machines are between pistons and bushings, sliding shoe and swash plate, as well as between cylinder block and valve plate. The analysis of these contacts is imperative to improve the overall performance of the machine, since they influence its efficiency to a high extend. This paper focuses on the contact between the valve plate and the cylinder block.

High pressure forces acting on the cylinder block result in a tilted position, defining the shape of the interface with the valve plate. The tilted position is overlayed by the cylinder block's rotation, resulting in unfavorable lubrication conditions and high contact pressure.

Measures to actively influencing the cylinder block's position during its rotation is currently researched at ifas. Using pressure pockets in the kidney grooves of the cylinder block is one of these measures and presented in this paper. The investigation is done simulative and experimental, using a $140 \mathrm{~cm}^{3}$ pump on a special test rig, measuring the cylinder block movement. The results of this are presented in this paper.
\end{abstract}

Keywords: Axial piston pump, cylinder block, pressure pocket, tilting

\section{Introduction}

Axial piston machines are used in many mobile and stationary hydraulic systems, because they can deliver high volume flow rates at a high pressure with an overall efficiency of about $90 \%$ in modern units [1]. Figure 1 shows the main components of an axial piston pump. Tribological contacts in this machine are defined as surfaces moving relative to each other, separated by a thin fluid film. Essential pairings are the pistons with their respective cylinders/bushings, the sliding shoe with the swash plate and the valve plate with the cylinder block [1]. Nearly $90 \%$ of the overall efficiency [2] can be traced back to these contacts. The research and further development of these tribological contacts in axial piston machines is therefore of great importance in context of resource efficiency, climate protection and emission laws. In context with the goal of removing leaded materials [4], which are partially used in these contacts, several aspects need to be combined to allow for improvements coming from different stakeholders. 


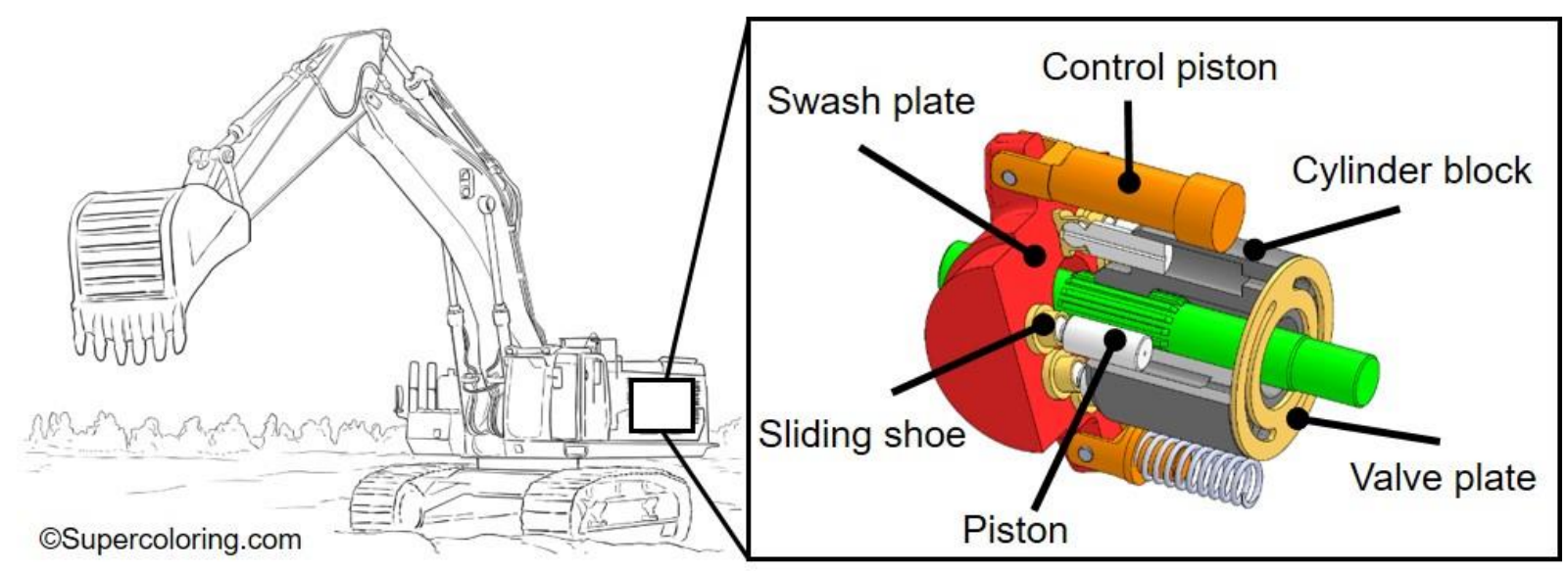

Figure 1: Main parts of an axial piston machine [3]

The here presented analysis focuses on the contact between the valve plate and the cylinder block. The cylinder block is driven by the shaft which in turn is driven by the engine. Axially it is in contact with the stationary valve plate which inherits kidney shaped openings, connected to the inlet and outlet ports of the pump. The cylinders in the cylinder block are connected via bores to the interface and due to the rotational movement, each cylinder transitions from the low pressure port to the high pressure during each rotation, synchronized with the suction and pressure stroke of the piston. Therefore, this is a forced commutation. The main task of the interface is to seal high and low pressure areas and openings against each other and the housing/ambient pressure. To reach the sealing function, the axial gap between cylinder block and valve plate must be as small as possible, however the system should not introduce unnecessary friction. Therefore, it is designed as hydrostatic/hydrodynamic axial bearing, incorporating the described functionality. Pressurized surfaces within the cylinder block are balanced against the area of the axial bearing, compensating the acting forces with a small remaining force acting as "gap-closing" force, always ensuring a safe operation. Springs acting on the cylinder block create a preload force, pressing the cylinder block against the valve plate. This creates an offset to the force balance and accounts for low-pressure operations, going along with low pressure forces and the risk of a lifting the cylinder block off the valve plate. Forces acting in gap-closing direction are designed so that a good compromise between friction and volumetric losses is established. However, a safety margin to prevent lift-off, unintended machine usage and dynamic effects must be implemented, moving the design point away from the sweet spot in the direction of higher friction. Another problem results then for self-sucking pumps. The increasing gap at low pressure side loses its function of sealing. Therefore, the pressure can collapse. This effect limits the self-sucking speed of axial piston pumps.

To account for tolerances, unfavorable lubrication conditions, high load peaks and to allow a run-in, the materials are often selected to be steel on one component, paired with a soft material on the other part (e.g., brass or bronze alloy). Lead within the alloy improves the durability and robustness, however it's use is Hence lead is a toxic heavy metal and its use is strongly regulated in the EU due to its toxicity.

Due to unbalanced forces resulting from the pressure difference between the high and low pressure apertures, the cylinder block tilts during operation. By setting up the equilibrium of the forces and moments acting on the cylinder block, P. Achten investigates the tilting effect analytically in [5]. The obtained results showed that the forces and moments are heavily unbalanced during operation, mainly due to two characteristics of axial piston machines. First, greater differences in fluid volume in each displacement chamber are caused by different rotational angles of the swash plate, thus causing uneven centrifugal forces. Also, compressive forces resulting from the narrowing of the cross-section of the cylinder block bores are very different, especially in operation points with high load pressures. Therefore, the resulting pressure difference between the low pressure side and the high pressure side grows bigger, so that the cylinder block gives in towards the high pressure side. A simulation model was built up by S. Wegner for the investigation of the cylinder block's movement. The description and validation of the model can be found in [6]. It is shown that the cylinder block tilts to the high pressure side and holds the attained position almost constantly during constant operating conditions, therefore supporting the statement of P. Achten's investigation. The position of the minimum gap height of a 9 piston machine, while 4 and 5 pistons are pressurized, is shown in fig. 2. The shown simulative results are consistent with experimental investigations [6]. 


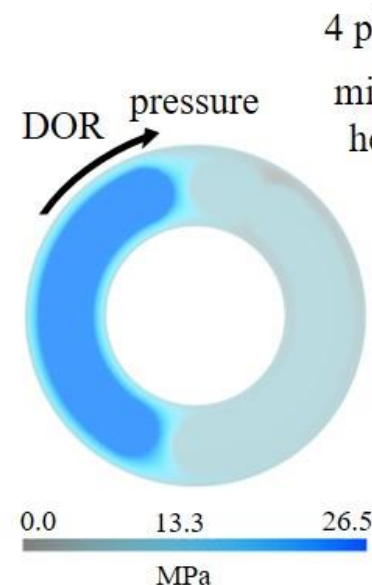

4 pistons

min gap height

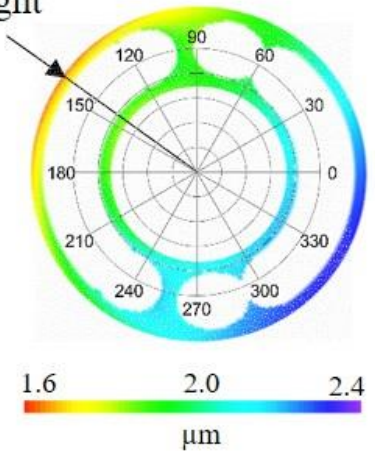

5 pistons

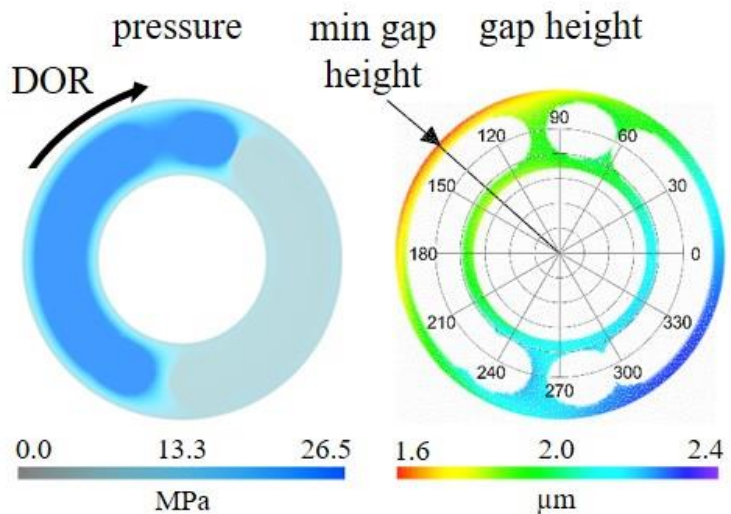

Figure 2: Position of minimum gap height [6]

Due to the negative effects named earlier, small gap heights increase the risk of high wear due to increased friction as well as local hot spots [7]. Especially the high temperature is a challenge for the material substitution. Coatings like "Diamond Like Carbon" (DLC) are very hard and have good tribology properties but are sensitive to high temperatures. Therefore, the development of design concepts with the aim to reduce tilting and temperature are of great interest.

In the context of this work, there are some interesting approaches. In [8], a concept with punctual pressure field is presented. Bores are positioned in the outer support ring of the valve plate and connected to the high-pressure kidney . The resulting pressure field reduces the cylinder block's tilting. A speed increase of $15 \%$ in self-priming mode of the pump results. The additional manufacturing expenditure a disadvantage of this concept. In addition to the relief bores, the connecting bores must be drilled from the outside into a round surface and must then be sealed by a plug. The manufacturing of the relief bores into a spherical valve plate is very difficult and therefore expensive and there must be enough space in the sealing gap for these bores. Due to the additional leakage, the volumetric efficiency decreases. The aim of another concept is to avoid the tilting of the cylinder block by an additional device [9]. Compensation pistons are installed and connected to the flow channel to add a moment against the tilting. In [10] a concept with externally pressurized pressure pockets in the valve plate is patented. The moment against the tilting can therefore be controlled independently of the operating point. The disadvantages are the additional manufacturing costs and that the complex application of the control for each operating point. S. Haug investigates and extends these concept [11][12] and applies it to other tribological contacts. He develops an operating point dependent control and could prevent the tilting for all investigated operation points almost completely in this way. P. Achten investigates the effect of additional pressure pockets in the barrels of a floating cup axial piston [13]. They are connected with groves to the bores and build up a hydrostatic bearing in the contact between the barrel and the port plate.

This work presents a new design concept for the cylinder block and its experimental investigation. Pressure pockets are placed at the outlet bores of the cylinder block. The underlying idea is to add an imbalance which relieves the area of minimum gap height for a short time to avoid the local temperature hot spots.

\section{Concept Development}

The development process is based on a simulation study with the simulation model, described in [6], developed at ifas. After a short explanation of the program, this chapter presents the simulation study and its results.

\subsection{Simulation Model}

A simulation model was created set up for the detailed analysis of the tribological contact between the cylinder block and the valve plate. The simulation is a continuation of tribological simulations specialized on interfaces in hydraulic pumps [14]. A detailed explanation is given in [6], and will only be briefly described in this work. In fig. 3 the principle of the simulation is depicted. The following physical effects are included:

- Fluid behavior using the Reynolds equation discretized on finite volumes

- Lumped parameter simulation calculating the cylinder pressures in each time step 
- Input of external forces, either quasi-static via look-up table or coupled to pressure variables resulting during the simulation

- Contact pressure (Greenwood and Tripp/Williamson model)

- Solid friction using the contact pressure acting on each finite volume (the interface surface)

- Fluid friction

- Solid body movement of the cylinder block

- Surface deformation

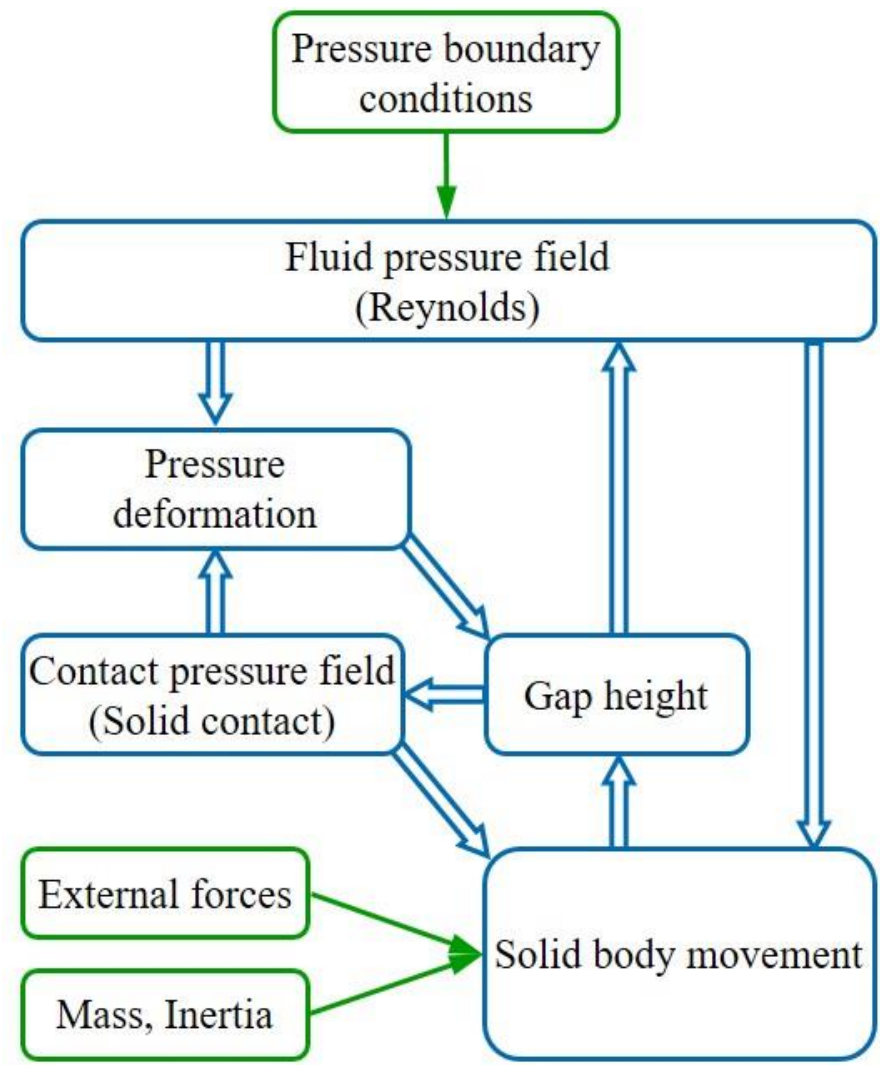

Figure 3: Chart of the Simulation model [15]

In each time step, the lumped parameter simulation is set up first, analyzing connections between cylinder block and valve plate features and creating a non-linear set of equations. The result is a defined pressure value for each feature (e.g. cylinder block piston pressure or valve plate port pressure) which is a boundary condition for the second set of non-linear equations, covering the aforementioned physical effects. The implicit Euler method is implemented as integration method, the set of equations is solved using the monolithic approach using the solver KINSOL [16].

\subsection{Simulation Studies}

The development process of the new design concept presented in this work starts with the simulation pre-study, which is published in [15] and is only shortly concluded in the following. This study investigated the effect of additional forces, moving with the cylinder block at a defined radius, derived from the kidney's shape. For the investigation of the effect of an additional imbalance, the forces are only active in the area of minimum gap height. With one force of $1.25 \mathrm{kN}$, acting at radius of $45.55 \mathrm{~mm}$, which is the outer shape of the kidney, the minimum gap height is shortly increase of about $5 \%$, compared to the standard version. This leads to a reduction of the contact pressure of over $25 \%$ and reduces therefore also the thermal load.

Additional forces can be installed by pressure pockets. In another design concept, presented in [15], these are placed at the high pressure kidney of the valve plate. The result is a static pressure field which creates a constant moment against the tilting. First experimental results show that this concept reduces the friction torque within the interface. To create the aforementioned effect of an additional imbalance, the pressure pockets are placed on the 
cylinder block. In this way, the forces investigated in the pre-study can be replicated, because of the pressure pockets are at high pressure side, they have great effect. But when they are at low pressure side, they have near no influence. In the concept of P. Achten [13], the surfaces are machined separated to the bores and then connected by groves to it. Another possibility, which is more easy to machine, is to integrate the pockets direct into the shape of the kidneys. Another advantage is that the pressure build up in the pockets is immediately when the bore joins the high pressure area. The limiting factor for these surfaces is the minimum sealing gap width. It should lay in the interval between 0.125 to 0.175 times the bore diameter [17]. For the geometry of the axial piston pump the sealing land should be $3.125 \mathrm{~mm}$. The maximum width is then $0.925 \mathrm{~mm}$ for the outer and $3.125 \mathrm{~mm}$ for the inner pressure pocket. Figure 4 shows the new design of the cylinder block's kidney shape in CAD and the prototype with their measured surfaces.

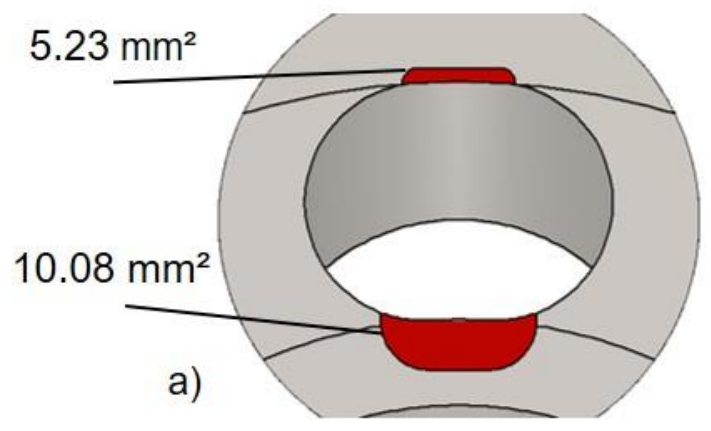

b)

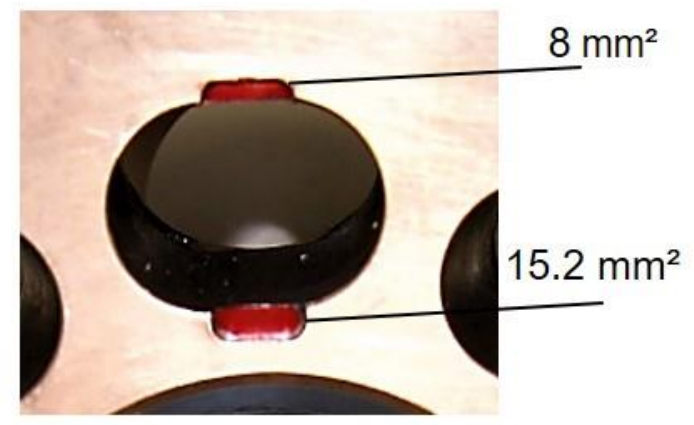

Figure 4: Additional pressure pockets a) CAD and b) prototype

The outer pocket is designed with the maximum width, while for the inner one $2 \mathrm{~mm}$ are used. This shape was then added to the simulation model for the analysis of this design concept. The main point of interest of the simulations was to investigate the effect of the pressure pockets in different configurations. The full study and its results are to find in [18] but are briefly explained here. The 12 different geometries, which are used are shown in fig. 5. Kidneys with the additional pressure pockets are black marked. They are measured and compared for one operation point with a rotational speed of $1500 \mathrm{rpm}$ and a load pressure of $250 \mathrm{bar}$. Configuration one is the standard geometry without pressure pockets. The effect of a raising number of additional surfaces, which are asymmetrical distributed, is investigated with the versions two up to version ten. In the configurations eleven and twelve, the pockets are installed symmetrically.

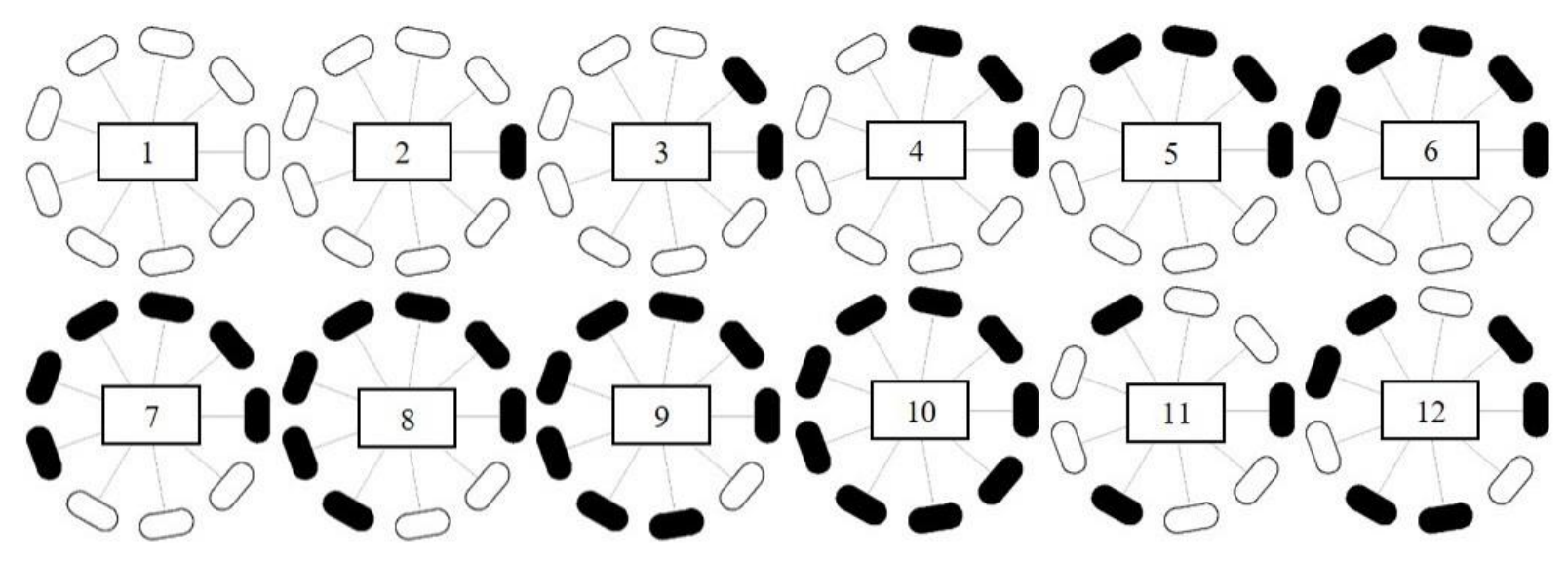

Figure 5: Investigated configurations

The simulation results show that the gap height is increased by the additonal pressure pocktes. Therefore, all configurations reduce the contact pressure from $17 \%$ in case of one modified kidney to over $50 \%$ for the version ten, where all are extended with the additional surfaces. Figure 6 shows the simulation results für the relative change of the tilt angle. The tilt angle of the cylinder block is only reduced for the configuration two and three with a small effect of less than $5 \%$. In the other versions with a higher number of pressure pockets, the tilting of the cylinder block increases. A possible explanation for this effect is that the increased gap height simply allows for more tilting until the contact pressure counters the movement. The concept idea to add an additional imbalance finds its maximum with the configuration six. As explained previous, there are two extrem points in an axial piston pump with nine pistons, when four or five kidney are pressurized. The maximum amplitude is reached, when five 
modified cylinder block bores are pressurized, while the four cylinder block bores with standard geometry are in contact with the low-pressure kidney of the valve plate.

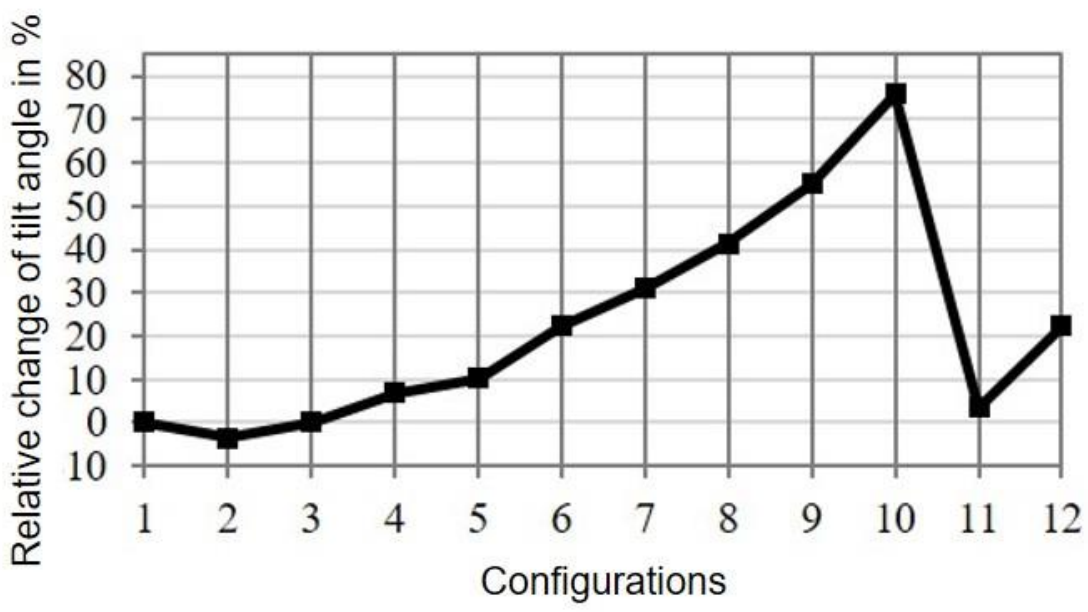

Figure 6: Relative change of the tilt angle for the considered configurations

The effect of an additional imbalance on the operating behavior of the pump cannot be estimated in advance. For this reason, a prototype was initially manufactured. For the initial test, configuration two was selected. Simulations for several operation points were carried out and evaluated. The operating points for the simulation are: speed (n) from $250 \mathrm{rpm}$ to $2500 \mathrm{rpm}$ in steps of $250 \mathrm{rpm}$; load pressure (p) from 50 bar to 250 bar in steps of 50 bar. The results for the minimum gap height (h) and the contact pressure (cp) are to shown in fig. 7 and fig. 8. The change of minimum gap height depends on the load pressure. This was expected. With the increasing speed, the effect of the pressure pockets is decrease by dynamical effects. The maximum reduction of the contact pressure is of near $15 \%$ at low speed while maximum pressure.
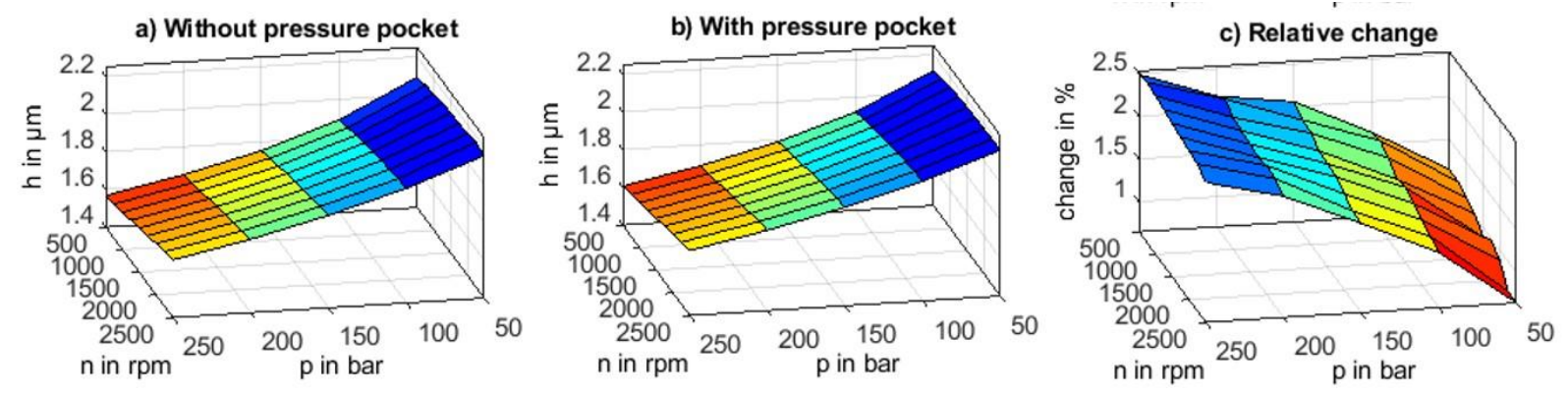

Figure 7: Minimum gap height and its relative change
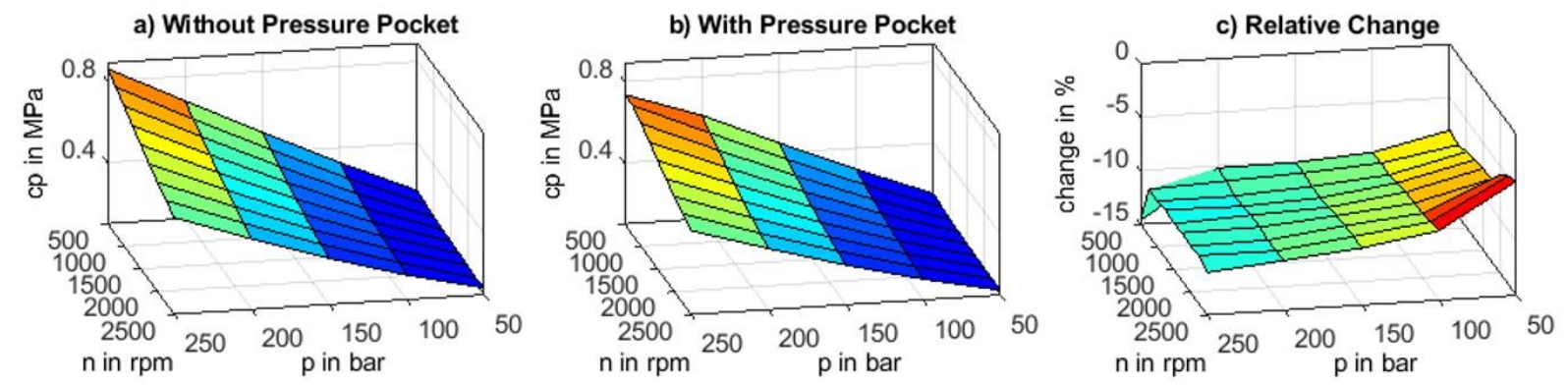

Figure 8: Contact pressure and its relative change 


\section{Experimental Investigation}

\subsection{Test Rig}

For the experimental investigation of the tribological contact focused in this work, a test rig was developed and built up at the institute, shown in fig. 9. The test pump (p1) is driven by a $160 \mathrm{~kW}$ motor. s5 and s6 are used for torque, speed and angular position measurement. Oil delivered from the filling pump p2 is filtered through f1. At the inlet and outlet of the test pump pressure (s2 \& s9) and temperature (s2 \& s8) are measured, the outlet flow is measured by s10. The load pressure is controlled by the load valve block (LV). The pump p4 delivers the fluid for the hydrostatic bearing (explanation in the following). The bearing pressure is set by valve (B). The leakage of the hydrostatic bearing and the test pump is delivered to the tank by the pump p3. In the secondary circuit, which includes the pump $\mathrm{p} 5$, the filter $\mathrm{f} 2$ and the water cooler $\mathrm{c} 1$, the oil is conditioned.
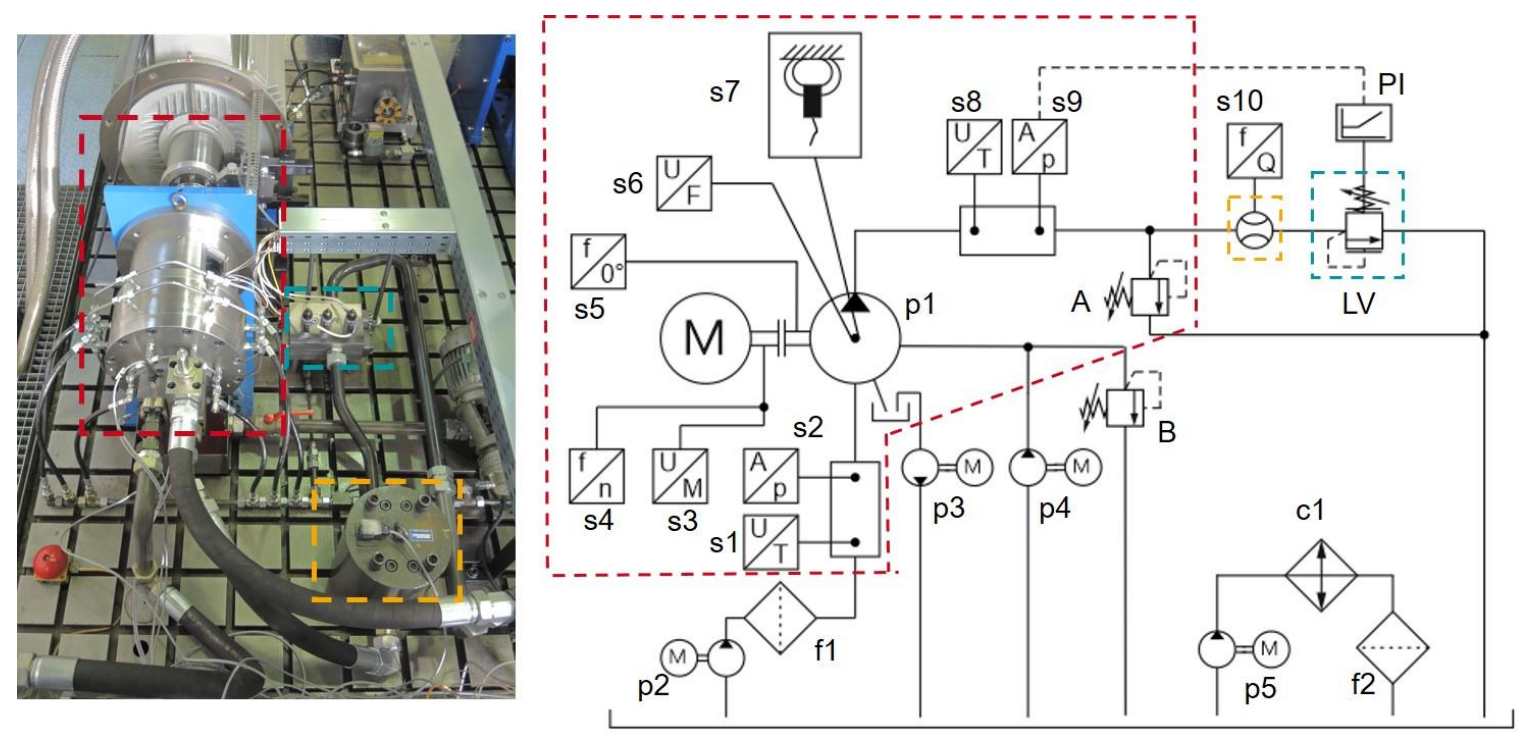

Figure 9: Test rig and hydraulic circuit diagram

The test bench was dimensioned for the analysis of a $140 \mathrm{~cm}^{3}$ axial piston pump with a maximum pressure of 340 bar and a maximum drive speed of $2400 \mathrm{rpm}$. The main drive components are placed in the test pump, which is presented in fig. 9. For the measurement of the friction torque between the valve plate and the cylinder block, a hydrostatic bearing was developed, which is also part of the test pump. The swash plate angle can be adjusted by means of spacers with the fixation bolt from $0^{\circ}$ to $16^{\circ}$. The main components of the hydrostatic bearing are the housing (blue) and the inner runner (green), which is externally pressurized. Six eddy current sensors (s7 in fig. 8), three in radial direction (black arrows in fig. 10) and three in axial direction (red arrows in fig. 10) are installed for the measurement of the cylinder block's movement as well as the gap height.

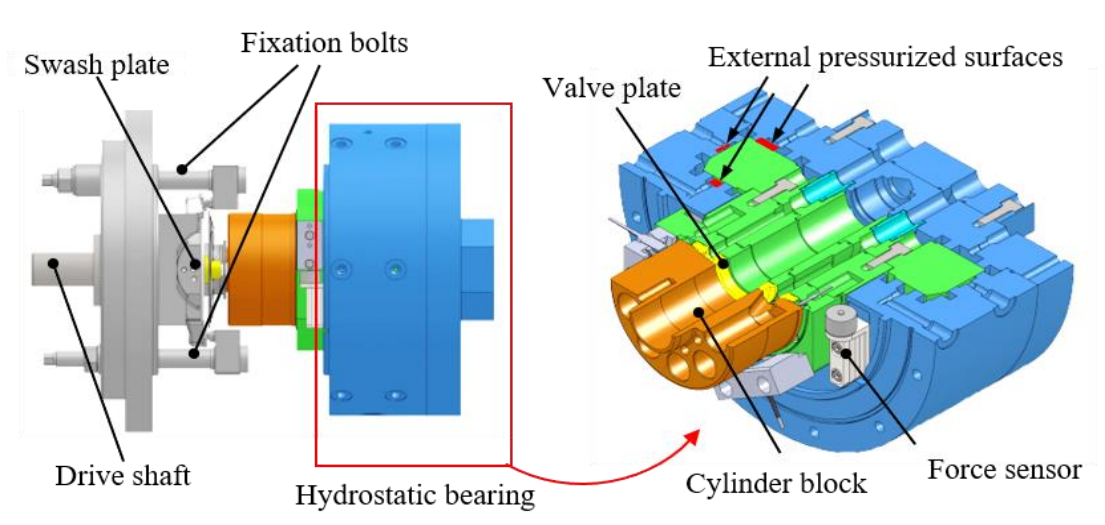

Radial sensor locations (black arrows)

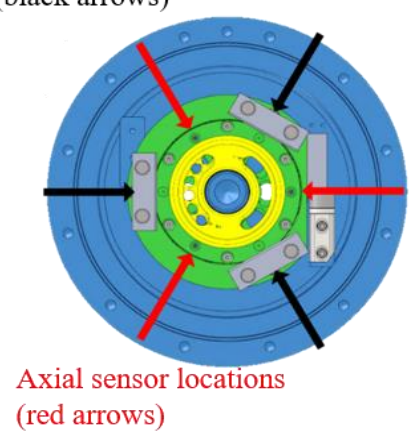

Figure 10: Drive train of the test pump and detailed view of the hydrostatic bearing [19] 


\subsection{Experimental Results}

Due to the risk of damaging the test rig or the sensor system in the start-up of the first test series, the test pump was not fully loaded. The range of rotational speed was limited to $1000 \mathrm{rpm}$, setting measuring points every $250 \mathrm{rpm}$ for the initial tests. The pressure was limited to $250 \mathrm{bar}$, increasing from $100 \mathrm{bar}$ in $25 \mathrm{bar}$ steps for each speed. The swivel angle was set to $8^{\circ}$, resulting in a displacement of $70 \mathrm{~cm}^{3}$. The hydrostatic bearing was pressurized to 100 bar. The suction side was set to a pre-load pressure of 8 bar. All measuring points were approached three times. Figure 10 shows the measured friction torque between valve plate and cylinder block for the standard configuration (gray) and the modified component (indicated with (Pro) in black). As expected from previous investigation, both configurations show a linear increase of the frictional torque at different pressure and speed level.

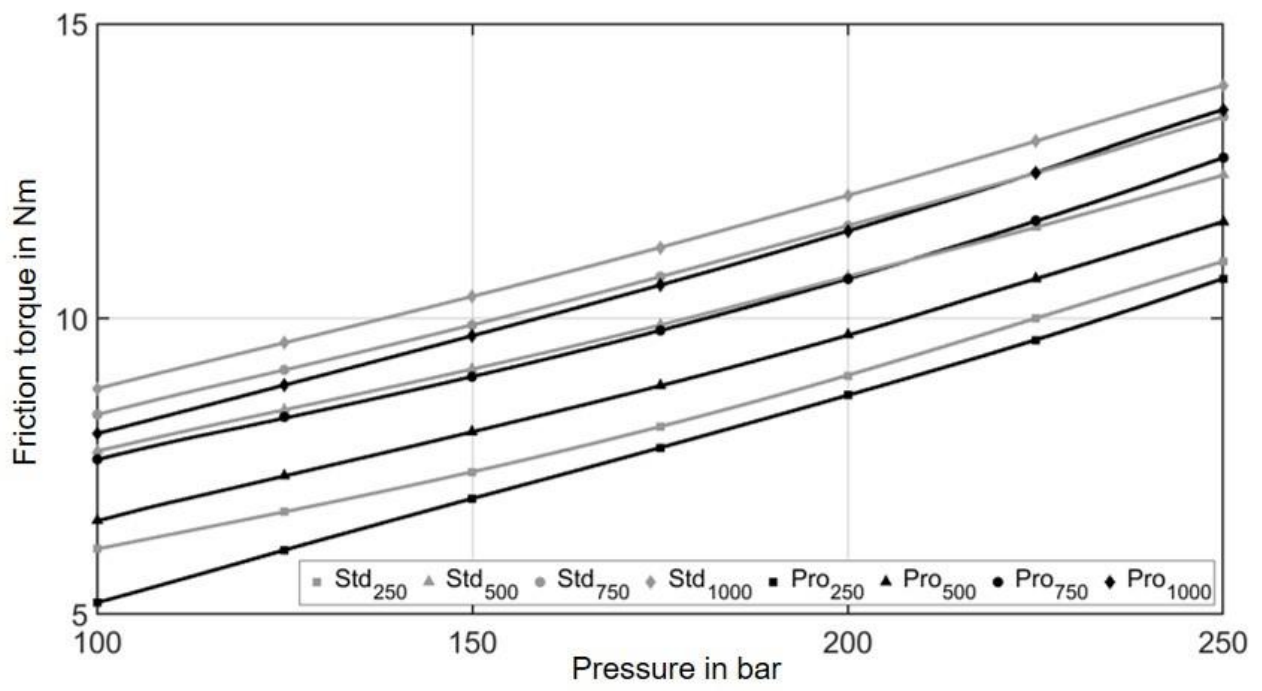

Figure 11: Friction torque for different pressure levels and rotation speeds

The relative change in frictional torque is plotted in fig. 12. In the prototype configuration, the friction torque is significantly reduced in all measuring points. At 100 bar, the largest friction torque reduction is measured over the measured speeds range, reaching a maximum reduction of about $15 \%$ at $250 \mathrm{rpm}$ and $500 \mathrm{rpm}$. With increasing load pressure, the reduction decreases almost linearly, but is still significantly reduced at 250 bar. The relative change in volumetric efficiency is shown in fig. 13. Particularly at low rotational speed, leakage increases notably, resulting in a significant reduction in volumetric efficiency. With increasing speed, this effect is less predominant, amounting to a maximum of about $2 \%$ efficiency reduction. 


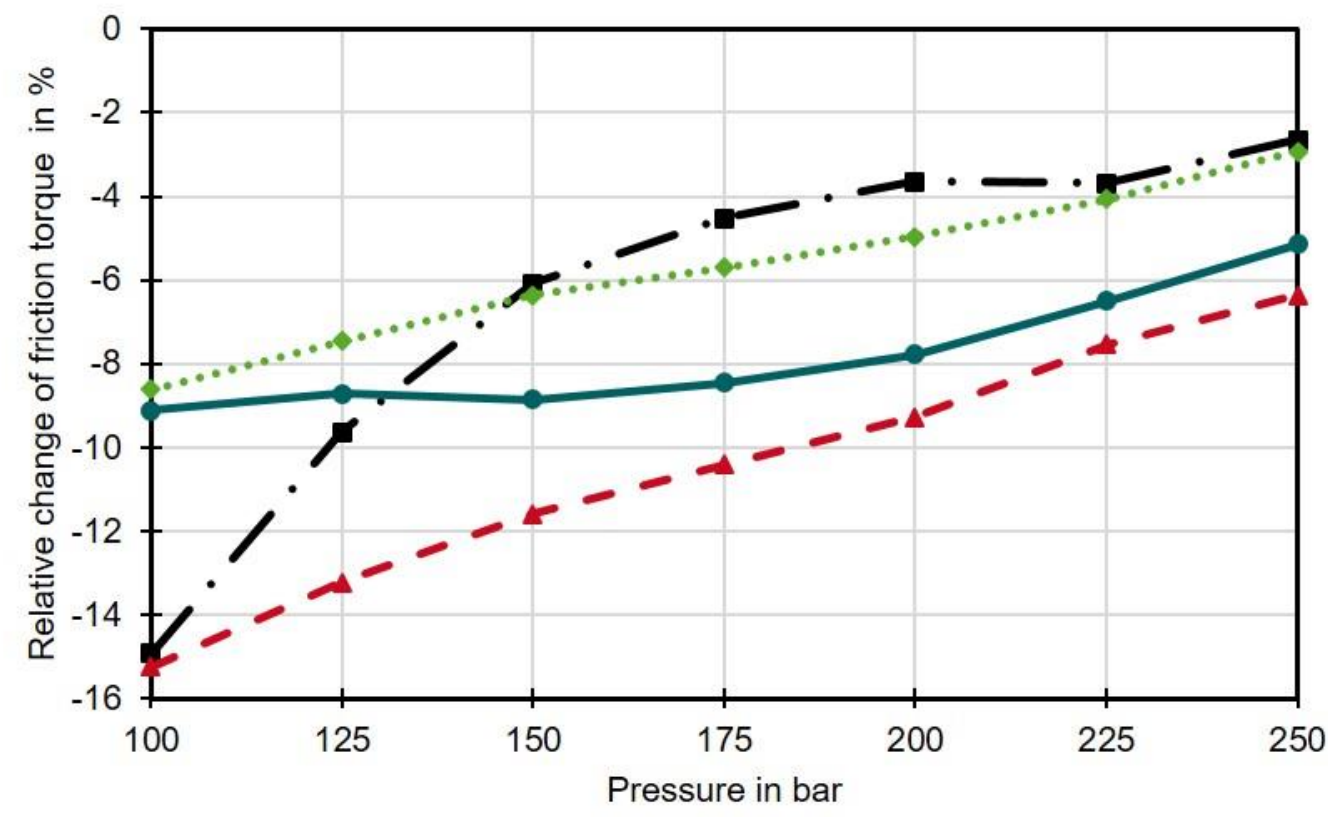

$\rightarrow 250 \mathrm{rpm} \quad-\Delta-500 \mathrm{rpm} \longrightarrow 750 \mathrm{rpm} \cdots 1000 \mathrm{rpm}$

Figure 12: Relative change of friction torque

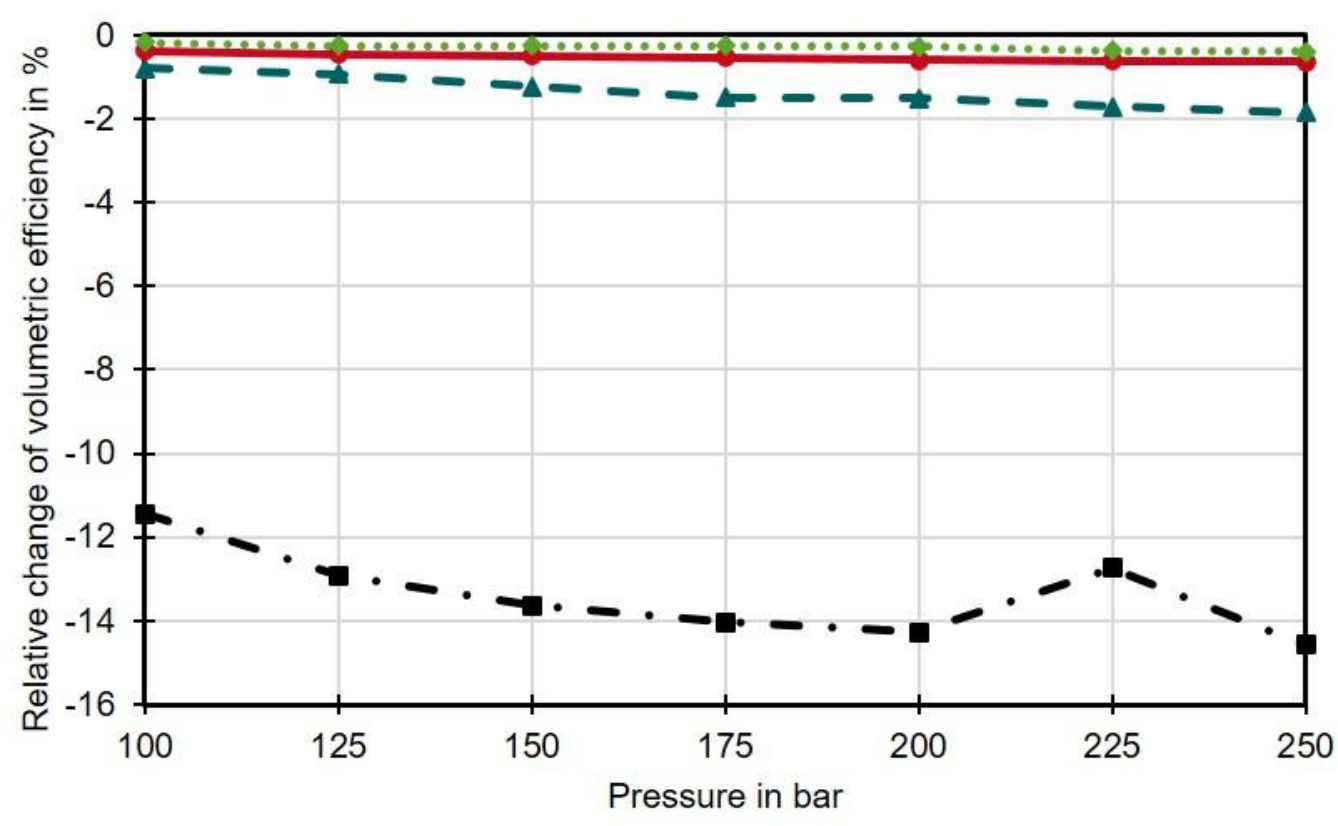

-ா. $250 \mathrm{rpm} \quad-\Delta-500 \mathrm{rpm} \longrightarrow 750 \mathrm{rmm} \cdots 1000$

Figure 13: Relative change of volumetric efficiency

The goal of the design concept is to install an additional imbalance. Therefore, the measurements of the eddy current sensors are compared in the following. Using the same coordinate system from fig. 2, the black h1 line denotes the axial and radial sensor position at $60^{\circ}$, the red $\mathrm{h} 2$ line at $180^{\circ}$ and the green $\mathrm{h} 3$ line at $300^{\circ}$. The sensor position is visualized in fig 14 . 


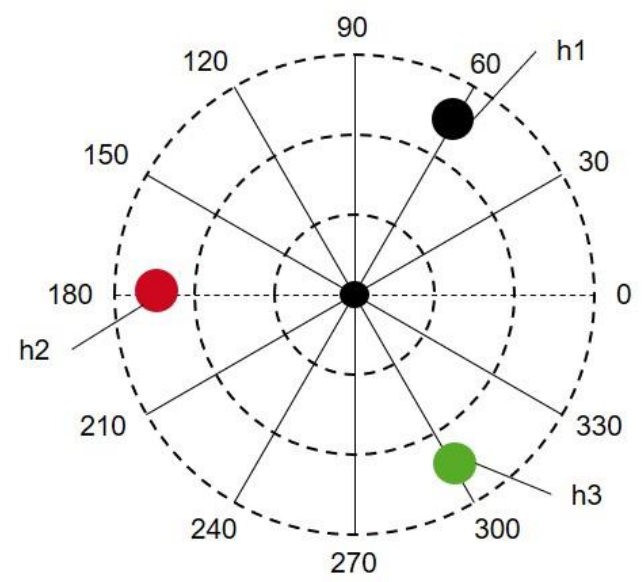

Figure 14: Sensor position of the axial and radial eddy current sensors

Different alloy compositions of the cylinder block material affecting the eddy-current sensors, machining inaccuracies of the targeted surface, differences in height adjustment of the sensors and further imperfections of the rotating system. For a better understanding, the raw sensor signal of h2, the distance to target (cylinder block), over one rotation at 100 bar (blue line) and 250 bar (red line), which therefore includes all of the pre named influences is plotted in fig. 15. However, the gap height reduction from 100 bar to 250 bar at high pressure region is clearly visible. The movement of the cylinder block depending on the pressurization of each of the nine pistons can be identified better in the red line as in the blue one.

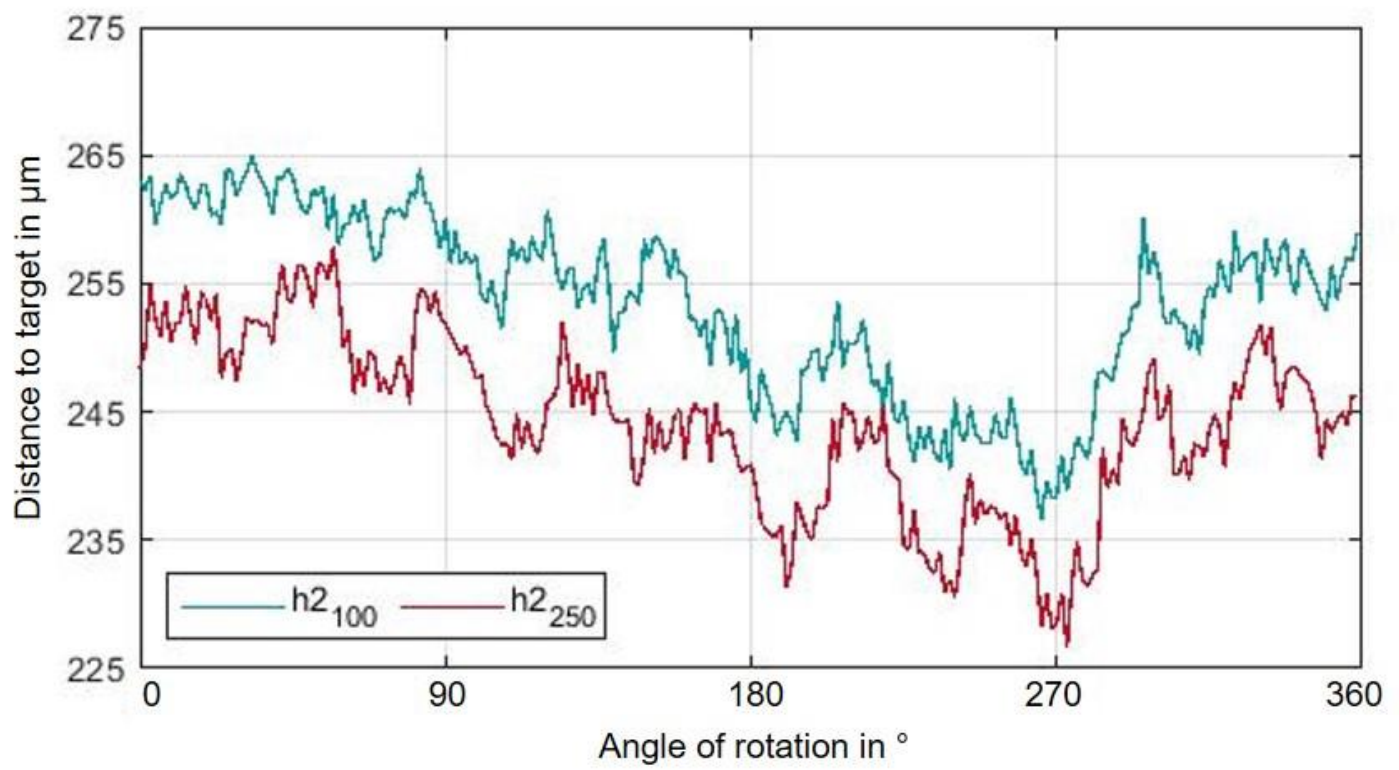

Figure 15: Raw sensor signal of h2 for 100 bar and 250 bar

For the analyzation of the influence of the new design to the movement of the cylinder block, the measured distance to target is averaged over one revolution and then compared for the operation points at 100 bar and 250 bar, by building the difference between this two points. This is done for all considered drive speeds. Figure 16 shows the change of distance for the axial eddy current sensors h1 (black), h2 (red) and h3 (green) for the prototype (full line) and the standard (dashed line) configuration. From the simulation results it was expected that the cylinder block tilts in way that a minimum gap height occurs at approx. $130^{\circ}$ (see fig. 2). The change of distance in fig. 16 show also this trend of the tilting direction. Compared to the high pressure operation point, the distance form $\mathrm{h} 1$ and $\mathrm{h} 2$ to the cylinder block is decreased, while it is increased for $\mathrm{h} 3$. For the prototype configuration the calculated change of distance is different. There is a lower reduction at $\mathrm{h} 2$ and a higher increase at $\mathrm{h} 3$. Very interesting is that the distance between $\mathrm{h} 1$ and the cylinder block is more reduced on average over one revolution. This indicates a change in the movement and therefore the tilt angle. 


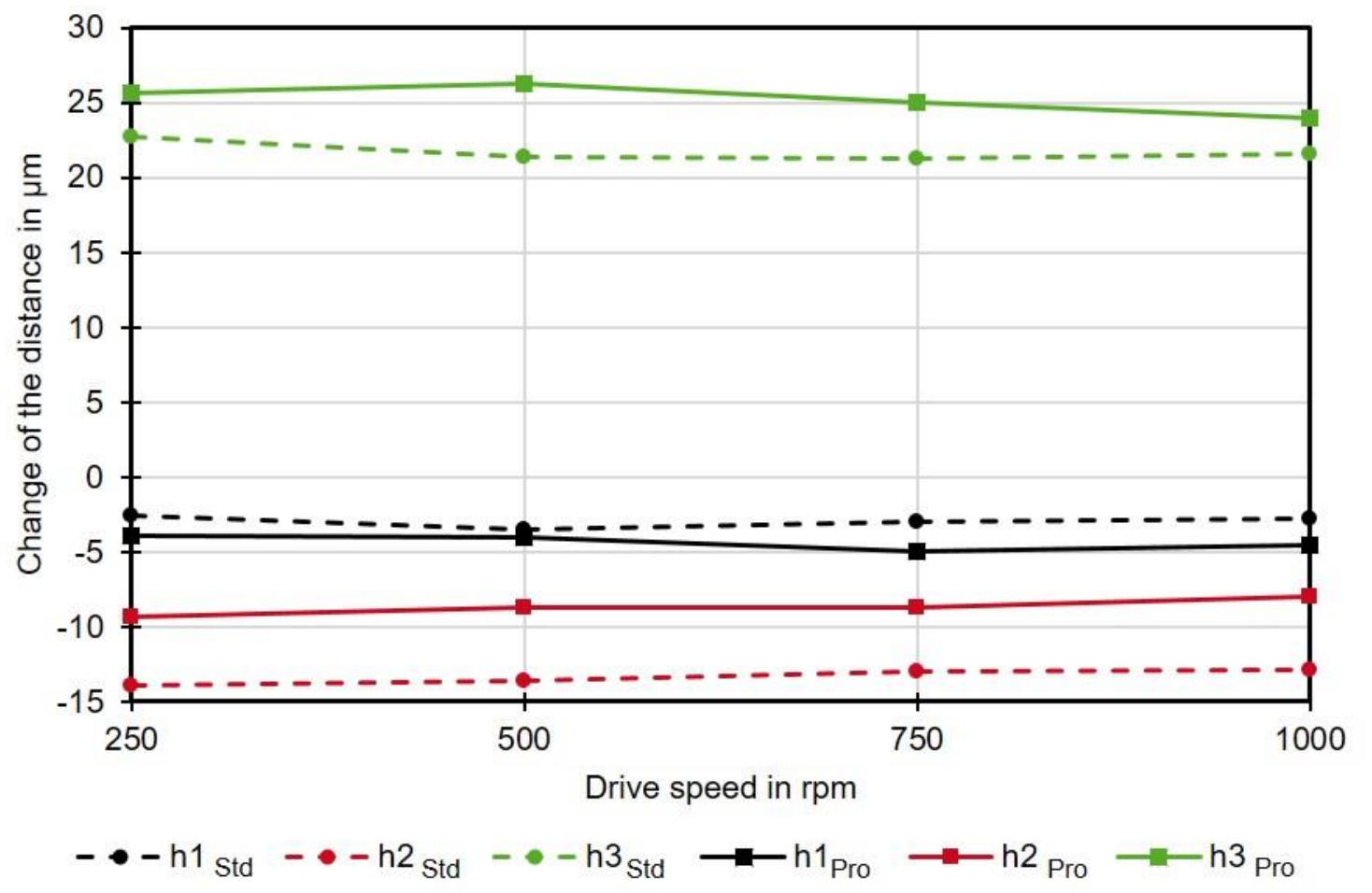

Figure 16: Change of distance from 100 bar to 250 bar for both configurations

For the understanding and visualization of the changed movement of the cylinder block, the orthogonal vector of the plane given by the measured distance of the axial sensors is calculated. Then, its direction is projected to a coordinate system. This method as well as the movement from 100 bar (origin) to 250 bar for all measurements is shown in fig. 17. The projection of the orthogonal vector lays in a very close area for the standard as well as for the prototype configuration. There is a significant change in the movement. While the cylinder block without pressure pockets tilts more to the high pressure side as expected from the simulations, the direction of the tilting for the prototype is very different.
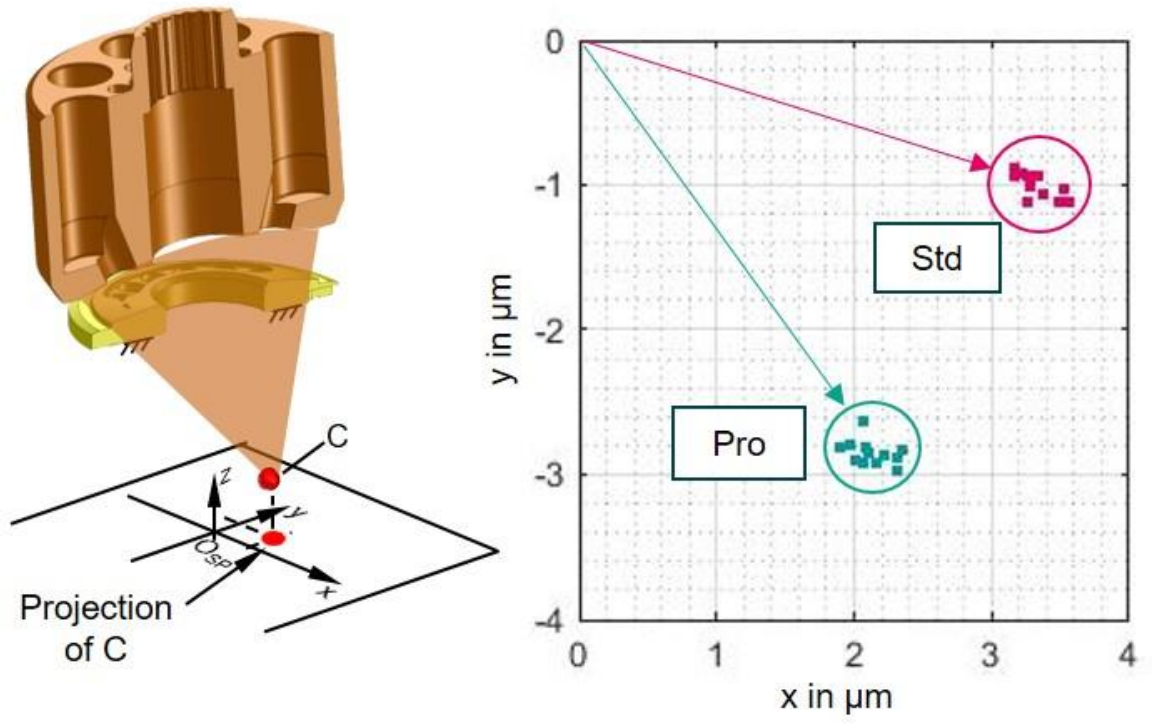

Figure 17: Projection of the orthogonal vector

\section{Conclusion and Outlook}

In a simulation study, fully presented in an earlier work of the author, the effect of additional pressure pockets was analyzed. Twelve configurations with a different number and position of pressure pockets are investigated in it. 
The greatest reduction of the cylinder block's tilting angle was calculated for the configuration with only one optimized kidney groove. Further simulations over a wide range of operating points, which are presented in this work, show that this design increase the gap height which leads to a significant reduction of the contact pressure. A prototype was machined and tested on the test rig. The experimental results show that the new design concept with the additional pressure pockets in on kidney of the cylinder block has significant effects to the tribological contact. The friction torque is reduced up to $15 \%$ for lower speeds, $250 \mathrm{rmp}$ and $500 \mathrm{rpm}$, at 100 bar. Because the part of fluid friction increases, the reduction of friction torque is lower for $750 \mathrm{rpm}$ and $1000 \mathrm{rpm}$. The difference between the standard and the prototype configuration decreases linearly with increasing load pressure, but is also significant at 250 bar. As it was expected, the volumetric efficiency is reduced. The smaller gap width, due to additional surfaces, has the same effect as a throttle where the length is reduced. Therefor the additional leakage is pressure depending and more or less statically for the different speeds. Because of this, the volumetric losses are at the higher speeds less than $2 \%$. The evaluation of the eddy current eddy-current sensor data two different load pressure operation points show that the standard cylinder block tilts to the high pressure side, thus confirming the simulation results and the previous study in [6]. Because of the imbalance added by the additional surfaces, the prototype cylinder block show on average over one revolution another tilting direction. This validates the simulations and the effect of the new design concept. Due to this imbalance, there is no local constant area of minimum gap height. This avoids the building of high temperature hot-spot in the tribological contact. The next steps are to validate the temperature effect by simulations and experiments.

\section{Acknowledgement}

This work was performed in the scope of the project "Increasing the efficiency of the cylinder block/valve plate contact in axial piston machines"/"Steigerung der Leistungsfähigkeit des Kolbentrommel-Steuerspiegel Kontaktes in Axialkolbenmaschinen" (MU41225/44-1), which is funded by the German Research Foundation (DFG). The authors would like to thank the German Research Foundation for funding the project.

\section{Nomenclature}

\begin{tabular}{|c|c|c|}
\hline Designation & Denotation & Unit \\
\hline$c 1$ & Cooler 1 & - \\
\hline$c p$ & Contact pressure & $\mathrm{MPa}$ \\
\hline DOR & Direction of rotation & - \\
\hline$f 1 \ldots 2$ & Filter $1 \ldots 2$ & - \\
\hline$h$ & Axial gap height & $\mu \mathrm{m}$ \\
\hline$h 1$ & Sensor position at $60^{\circ}$ & - \\
\hline$h 2$ & Sensor position at $180^{\circ}$ & - \\
\hline$h 3$ & Sensor position at $300^{\circ}$ & - \\
\hline ifas & $\begin{array}{l}\text { Institute for fluid power drives } \\
\text { and systems }\end{array}$ & - \\
\hline$L V$ & Load valve & - \\
\hline$n$ & Drive speed & $\mathrm{rpm}$ \\
\hline$p$ & Pressure & bar \\
\hline$p 1 \ldots 5$ & Pump $1 \ldots 5$ & - \\
\hline$P I$ & PI controller & - \\
\hline$s 1 \ldots 10$ & Sensor $1 \ldots 10$ & - \\
\hline
\end{tabular}

\section{References}

[1] M Gärtner. Verlustanalyse am Kolben-Buchse-Kontakt von Axialkolbenpumpen in Schrägscheibenbauweise, Dissertation, RWTH Aachen University, Aachen, 2019 
[2] $\mathrm{B} \mathrm{Xu}, \mathrm{M} \mathrm{Hu}, \mathrm{J}-\mathrm{H}$ Zhang, Z-B Mao. Distribution characteristics and impact on pump's efficiency of hydromechanical losses of axial piston pump over wide operating ranges. Journal of Central South University, 2017

[3] K Schmitz, H Murrenhoff. Grundlagen der Fluidtechnik Teil 1: Hydraulik, Shaker Verlag, Aachen, 2018

[4] Table of restrited substances under REACH, European Chemicals Agency

[5] P Achten, S. Eggenkam. Barrel tipping in axial piston pumps and motors, 15th Scandinavian International Conference on Fluid Power, Linköping, Sweden, 2017

[6] S Wegner, S Gels, H Murrenhoff. Simulation of the tribological contact cylinder block/valve plate and influence of geometry and operation points on the friction torque in axial piston machines, The 9th International Fluid Power Conference, Aachen, Germany, 2014

[7] R Ivantysyn, A Shorbagy, J Weber. An approach to visualize limiting factors in the cylinder block/valve plate gap in Axial Piston Pumps, ASME Symposiom on Fluid Power and Motion Control, Bath, Great Britain, 2017

[8] InLine Hydraulik GmbH, DE 19823353 A1, patent, Germany, 1999

[9] Linde AG, DE 19855899 A1, patent, Germany, 2000

[10] Robert Bosch GmbH, DE 102010006895 A1, patent, Germany, 2011

[11] S Haug, M Geimer. Optimierung von Axialkolbenmaschinen durch bedarfsangepasste Entlastung tribologischer Kontakte, 9. Kolloquium Mobilhydraulik, Karlsruhe, Germany, 2016

[12] S Haug, M Geimer. Optimization of Axial Piston Units Based on Demand-driven Relief of Tribological Contacts, The 10th International Fluid Power Conference, Dresden, Germany, 2016

[13] P Achten, R Mommers, J Potma, J Achten. Experimental Investigation of a Hydrostatic Bearing Between Barrels and Port Plates in Floating Cup Axial Piston Pumps, ASME Symposium on Fluid Power and Motion Control, Bath, Great Britain, 2020

[14] S Gels. Einsatz konturierter und beschichteter Kolben-Buchse-Paare in Axialkolbenmaschinen in Schrägscheibenbauweise, Dissertation, RWTH Aachen University, Aachen, 2011

[15] S Geffroy, N Bauer, T Mielke, S Wegner, S Gels, H Murrenhoff, K Schmitz, Optimization of the tribological contact of valve plate and cylinder block within axial piston machines, The 12th international Fluid Power Conference, Dresden, Germany, 2020

[16] A C Hindmarsh, P N Brown, K E Grant, S L Lee, R Serban, D E Shumaker, C S Woodward, SUNDIALS: Suite of nonlinear and differential/algebraic equation solvers, ACM Transactions on Mathematical Software (TOMS), 2005

[17] J Ivantysyn, M Ivantysynova, Hydrostatische Pumpen und Motoren, 1. Auflage, Vogel, Würzburg, Germany, 1993

[18] S Geffroy, S Wegner, S Gels, H Murrenhoff, K Schmitz, New Design Concepts for the Tribological Contact of Cylinder Block and Valve Plate, ASME Symposium on Fluid Power and Motion Control, Bath, Great Britain, 2020

[19] S Wegner, F Löschner, S Gels, H Murrenhoff. Validation of the physical implementation in a simulation model for the cylinder block/valve plate contact supported by experimental investigations, The 10th International Fluid Power Conference, Dresden, Germany, 2016 